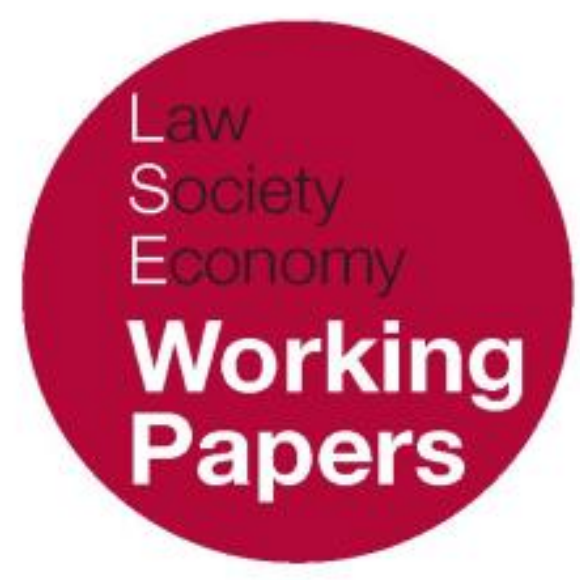

\title{
Regulating 'Platform Power'
}

\author{
Orla Lynskey
}

LSE Law, Society and Economy Working Papers 1/2017 London School of Economics and Political Science

Law Department

This paper can be downloaded without charge from LSE Law, Society and Economy Working Papers at: www.lse.ac.uk/collections/law/wps/wps.htm and the Social Sciences Research Network electronic library at: https://papers.ssrn.com/sol3/papers.cfm?abstract_id=2921021. (C) Orla Lynskey. Users may download and/or print one copy to facilitate their private study or for non-commercial research. Users may not engage in further distribution of this material or use it for any profit-making activities or any other form of commercial gain. 


\title{
Regulating 'Platform Power'
}

\author{
Orla Lynskey *
}

\begin{abstract}
Increasing regulatory and doctrinal attention has recently focused on the problem of 'platform power'. Yet calls for regulation of online platforms fail to identify the problems such regulation would target, and as a result appear to lack merit. In this paper, two claims are advanced. First, that the concept of 'platform power' is both an under and over-inclusive regulatory target and, as such, should be replaced by the broader concept of a 'digital gatekeeper'. Second, that existing legal mechanisms do not adequately reflect the power over information flows and individual behaviour that gatekeepers can exercise. In particular, this gatekeeper power can have implications for individual rights that competition law and economic regulation are not designed to capture. Moreover, the technological design, and complexity, of digital gatekeepers renders their operations impervious to scrutiny by individual users, thereby exacerbating these potential implications.
\end{abstract}

* Assistant Professor, Department of Law, London School of Economics and Political Science. 


\section{INTRODUCTION}

When John Perry Barlow penned the 'Declaration of the Independence of Cyberspace'1 it was governments, 'weary giants of flesh and steel', rather than private actors that threatened to jeopardise emerging governance structures in 'cyberspace'. ${ }^{2}$ Twenty years later, it is acknowledged that, contrary to early cyberlibertarian thinking, the Internet can be regulated ${ }^{3}$ and Internet governance is no longer the sole purview of the State. The State increasingly operates in tandem with online private actors in security and law enforcement ${ }^{4}$, in the provision of public goods ${ }^{5}$ and even to adjudicate what is in the 'public interest'. ${ }^{6}$ Moreover, online private actors are supported by States through private law rights and liabilities $^{7}$ and enabled to influence the behaviour of individuals through technological code. ${ }^{8}$ This private ordering by non-State actors impacts upon economic, social, cultural and political dimensions of our lives and can influence the conditions pursuant to which fundamental rights are exercised. One example of this is the way web 2.0 extends mass communication capabilities - traditionally only available to broadcasters - to individuals, thereby enhancing their expressive capacity. This extension of expressive capability has the potential to enhance the right to freedom of expression of individuals while at the same time it challenges the legal framework applicable to free speech. ${ }^{9}$

\footnotetext{
1 John Perry Barlow, 'A Declaration of the Independence of Cyberspace', 8 February 1996, available at https://www.eff.org/cyberspace-independence (all links last accessed 8 March 2016).

2 Ibid.

3 See, for instance, Jack L Goldsmith, 'Against Cyberanarchy' (1998) 65 Chicago Law Review 1199, or Joel Reidenberg, 'Lex Informatica: The Formulation of Information Policy Rules Through Technology' (1998) 76 Texas Law Review 553.

4 The PRISM and Tempora surveillance programmes revealed by Edward Snowden illustrate the symbiotic relationship between State and corporate data collection and processing. These programmes have been subject to legal challenge before domestic and international courts and tribunals (see, for example, Liberty \& Ors $v$ Secretary of State for Foreign Affairs \& Ors [2015] UKIPTrib 13 77-H).

5 For instance, search engine Google has collaborated with several public libraries (including the Australian National Library, the Bavarian State library and New York Public Library) as part of the Google Books Library Project. For further information about the project and institutional partners, see https://www.google.com.au/googlebooks/library/.

${ }^{6}$ For instance, it follows from the EU Court of Justice ruling in Case C-131/12 Google Spain SL v AEPD ECLI:EU:C:2014:317 that when determining whether an individual can exercise his or her right to delete pursuant to data protection rules, Google (or the data controller) must assess whether an overriding public interest in retaining the links to the relevant information exists (at [97]). For a dissection of Google's influence over the subsequent debate see Julia Powles, 'The Case That Won't be Forgotten' (2015) Loyola University Chicago Law Journal 583.

7 Mark A Lemley, 'Terms of Use' (2006) Minnesota Law Review 459, and Woodrow Hartzog, 'Website Design as Contract' (2011) 60 American University Law Review 1635.

${ }^{8}$ Lawrence Lessig, Code and Other Laws of Cyberspace, Version 2.0 (Basic Books, 2006).

${ }^{9}$ Rowbottom argues that European free speech jurisprudence traditionally protects speech that is in the public interest and that the digital dialogue and everyday conversations now captured by laws regulating is therefore given inadequate protection. See, Jacob Rowbottom, 'To Rant, Vent and Converse: Protecting Low Level Digital Speech’ (2012) 71 Cambridge Law Journal 355.
} 
This power of Internet intermediaries - recently labelled 'platform power' has been the subject of increasing doctrinal and media attention. ${ }^{10}$ For instance, Cohen has argued that successful state regulation of the information economy will, amongst other things, require an 'analytically sound conception of platform power' and 'coherent and publicly accountable methods for identifying, describing and responding to systemic threats'. ${ }^{11}$ 'Platform power' is also becoming a prominent feature on public policy and regulatory agendas, particularly across Europe. ${ }^{12}$ The European Union (EU) pinpointed this issue for further attention in a 2015 Communication setting out its strategy for a Digital Single Market for Europe. It noted that:

Some online platforms have evolved to become players competing in many sectors of the economy and the way they use their market power raises a number of issues that warrant further analysis beyond the application of competition law in specific cases..$^{13}$

This marks a turning point as, to date, regulators have assumed that the application of ex post competition law (or antitrust) rules, designed to ensure that companies with market power will not exclude equally efficient competitors or engage in exploitation, negates the need for the ex ante regulation of platforms. This paper challenges this assumption and highlights how existing legal mechanisms, including competition law, may not capture the power over communications exercised by digital platforms.

In order to illustrate this point, and to contribute to the continuing debate on platform power, two main claims are advanced. The first claim is that the term 'platform power' fails to reflect the potentially problematic power at the heart of the information society. Focus should therefore shift from this concept to the identification of concerns raised by the practices of Internet intermediaries. This is

\footnotetext{
10 Joe Kennedy, 'Don't regulate internet platforms, embrace them', 14 November 2015, EurActiv (http://www.euractiv.com/section/digital/opinion/don-t-regulate-internet-platforms-embrace-them/); Tom Fairless, 'EU Digital Chief Urges Regulation to Nurture European Internet Platforms', 14 April 2015, The Wall Street Journal (http://www.wsi.com/articles/eu-digital-chief-urges-regulation-to-nurtureeuropean-internet-platforms-1429009201).

${ }^{11}$ Julie Cohen, 'The Regulatory State in the Information Age' (2016) 17(2) Theoretical Inquiries in Law (forthcoming). Available at SSRN: http://ssrn.com/abstract=2714072. Cohen defines 'platform power' as the "power to link facially separate markets and/or to constrain participation in markets by using technical protocols.'

${ }^{12}$ Conseil National du Numerique (CNNum), 'Platform Neutrality: Building an open and sustainable digital environment', May 2014 (available at http://www.cnnumerique.fr/wpcontent/uploads/2014/06/PlatformNeutrality_VA.pdf), 6. The French CNNum acknowledge the ability of internet platforms 'to create great value from the data retrieved from users', it also states that the use of this data must ensure respect for the 'data rights' of users and that individuals 'maintain sole control over the repercussions resulting from the use thereof' and 'benefit from the use of their data'. It concludes that 'recent events have illustrated that current practices do not make it possible to reach these goals.'

13 Communication from the Commission to the European Parliament, the Council, the European Economic and Social Committee and the Committee of the Regions, 'A Digital Single Market Strategy for Europe’ COM (2015) 192 final, 12.
} 
for three reasons: first, 'platform' is a contested and open-ended term making it a fluid, and thus inappropriate, target for regulation; second, 'power' has been interpreted synonymously with economic power to the exclusion of other types of power; and, third, although imperfect, a functional rather than a formalistic approach is preferred when identifying the targets of regulation. The second claim is that blind spots exist when the issue of 'platform power' is viewed solely through an economic lens. As a result, competition law (which is guided by the principles of Chicago School economics) will not necessarily capture and sanction practices that negatively impact upon non-economic parameters, such as freedom of expression and privacy. Nevertheless, it is necessary to acknowledge that the mere existence of regulatory gaps will not, of itself, justify the introduction of further measures to regulate platforms.

\section{2 'PLATFORM POWER': AN INAPPROPRIATE REGULATORY TARGET}

Analysis of whether 'platform power' should be (further ${ }^{14}$ ) regulated must be reframed if it is to yield valuable regulatory insights in the EU and other democratic states struggling with this question. In particular, the concept of 'platform' is fluid and over-inclusive while 'power' is often equated to 'market power' and is thus under-inclusive. Regulatory attention should focus on identifying and addressing potentially problematic conduct or processes that may require regulation rather than on the nebulous concept of 'platform power'.

\section{A. THE OVER-INCLUSIVENESS OF THE TERM ‘PLATFORM’}

As part of its Digital Single Market Strategy for Europe, the European Commission launched a consultation on the regulatory environment for platforms and intermediaries..$^{15} \mathrm{~A}$ central part of the Commission's investigation, likely pursued in response to political pressure ${ }^{16}$, 'centred on the question of whether, beyond the existing regulatory framework, new regulation for online platforms

\footnotetext{
14 Platforms are already subject to a broad array of legal and regulatory measures indicating that the question posed - should platforms be regulated - may also be incorrect starting point.

15 European Commission, 'Public consultation on the regulatory environment for platforms, online intermediaries, data and cloud computing and the collaborative economy' (September 2015). Available at: https://ec.europa.eu/digital-single-market/en/news/public-consultation-regulatory-environment-

platforms-online-intermediaries-data-and-cloud.

16 Numerous media outlets reported in May 2015 that French and German Ministers for the Economy (Emmanuel Macron and Sigmar Gabriel respectively) had written to the Vice President of the European Commission requesting such a consultation with the aim of establishing an appropriate general regulatory framework. See, for instance, Irish Times, 'Germany and France seek tighter internet regulations', 1 May 2015. Available at: http://www.irishtimes.com/business/technology/germany-and-france-seek-tighterinternet-regulations-1.2195888.
} 
should be introduced'. ${ }^{17}$ Yet although this and other initiatives are gaining momentum, the term 'platform' remains contested with little consensus on its definition.

The European Commission's Digital Single Market Communication does not define the term platform however a platform is defined in the Commission's public consultation as 'an undertaking operating in two (or multi)-sided markets, which uses the Internet to enable interactions between two or more distinct but interdependent groups of users so as to generate value for at least one of the groups. ${ }^{18}$ According to this definition the key characteristic of a platform is two or multi-sidedness. Yet, we must query why this feature is sufficient to merit regulation. ${ }^{19}$ First, it is well-established in economic theory that two or multisidedness may lead to positive externalities in the form of direct and indirect network effects: that is, 'greater involvement by agents of at least one type increases the value of the platform to agents of the other types' (indirect network effect) or agents of the same type (direct network effects). ${ }^{20}$ Secondly, multisidedness appears to be an arbitrary feature to target for regulation given that businesses can switch from being single-sided to multi-sided, and vice versa, with relative ease. For instance, Netflix - which is often labelled a digital platform provides a service only to end-users. ${ }^{21}$ It is therefore currently a single-sided service yet if it changed its revenue model and subsidised its content through advertising rather than through subscription fees it would become a two-sided platform. We must consider such a change in revenue model should be decisive in determining whether or not a digital actor is regulated.

Other definitions of a platform remove the explicit emphasis on two or multi-sidedness. ${ }^{22}$ For instance, a broader definition was proposed in a study commissioned by the European Parliament according to which 'a digital platform provides a (technological) basis for delivering or aggregating services/content from service/content providers to end-users'. ${ }^{23}$ This definition incorporates two and multi-sided platforms but seemingly also includes services such as Spotify and

\footnotetext{
${ }^{17}$ House of Lords - Select Committee on the EU, 'Online Platforms and the Digital Single Market', HL Paper 129, 20 April 2016, 7.

${ }^{18}$ European Commission, 'Public consultation on the regulatory environment' (n 15$) 5$.

${ }^{19}$ The work of economists on multi-sided markets informs the actions of regulators in the online sphere. See, in particular, Jean-Charles Rochet and Jean Tirole, 'Platform Competition in Two-Sided Markets' (2003)1(4) Journal of the European Economic Association 990, and David S. Evans and Richard Schmalenese, 'The Industrial Organization of Markets with Two-Sided Platforms' (2007) Competition Policy International 151

${ }^{20}$ Colin Blackman and Romain Bosc, 'What is a platform and should they be regulated? Summary report', Centre for European Policy Studies (CEPS), 17 November 2015. Comments of Nicolai von Gorp, (https://www.ceps.eu/sites/default/files/CEPS $\% 20$ What $\% 20$ is $\% 20 \mathrm{a} \% 20$ platform summary $\% 20$ report. pdf).

${ }^{21}$ TNO report, 'Digital platforms: an analytical framework for identifying and evaluating policy options', TNO 2015 R11271, Final report, 11.

22 Mansell proposes the following definition: a digital platform is a 'reconfigurable base of compatible components on which firms and users build applications'. Robin Mansell, 'Platforms of power' (2015) 43(1) Intermedia 20, 22.

${ }^{23}$ TNO Report, 'Digital platforms: an analytical framework' (n 21) 11; European Parliament, 'Challenges for Competition in a Digitalised Economy', Study for the ECON Committee, July 2015, 7.
} 
Netflix that simply offer a service in exchange for remuneration. Yet, even this definition appears to provide a simplistic account of the relationship platforms facilitate between 'providers' and 'users'. ${ }^{24}$ Moreover, it fails to shed light on why platforms might merit regulation. ${ }^{25}$ As observed before the House of Lords, other than being 'digital' (or offering a 'technological' basis), it is difficult to discern how a digital platform differs from offline 'platforms' that offer similar services, such as subscription television services and newspapers. The dividing line between online and offline platforms may also become increasingly blurred once an offline platform decides to develop an online presence. If the very fact of being 'digital' is decisive, it remains necessary to articulate why this is the case.

In an attempt to resolve this definitional dilemma, others have suggested that platforms should not be defined but instead classified according to a taxonomy based on their characteristics. ${ }^{26} \mathrm{~A}$ report commissioned by the Dutch government classifies platforms in four broad categories ${ }^{27}$ but recognises that within these categories platforms will differ with regard to characteristics such as their revenue model, whether they give rise to network effects, the use of platforms by other platforms or applications, geographic dependencies and data and content usage, amongst others. ${ }^{28}$ This approach reflects the fact that the term 'online platform' can cover a broad range of different types of platforms, the functions and characteristics of which could differ considerably. ${ }^{29}$ While this approach may be preferable, without identifying a particular category and combination of characteristics that may be problematic, it once again risks being overinconclusive. In light of this lack of clarity, it is suggested that it would be preferable to identify problematic practices that may require regulation rather than focusing on 'platform power'. 30

\footnotetext{
${ }^{24}$ This is evident from the ongoing debate on prosumption sparked in the Web 2.0 context primarily by Ritzer and Jurgenson. See, George Ritzer and Nathan Jurgenson, 'Production, Consumption, Prosumption: The nature of capitalism in the age of the digital "prosumer" (2010) 10(1) Journal of Consumer Culture 13.

25 Commentators have argued that it is difficult 'to identify characteristics uniquely shared by online platforms that might merit regulation'. Alex Chisolm - CMA Chief Executive, 'Platform regulation antitrust law versus sector-specific legislation: evolving our tools and practices to meet the challenges of the digital economy', 27 October 2015.

${ }^{26}$ See Blackman and Bosc, CEPS Report (n 20) 2. According to this report, the economic literature on multi-sided markets suggests that definitions should take into account at least three criteria: the balance of contributions; interdependence; control.

${ }^{27}$ These categories are: reseller/distributor; marketplace; social network; and platform of platforms. TNO report, 'Digital Platforms: an analytical framework' (n 21) 11.

28 Ibid. 12.

${ }^{29}$ Commission Staff Working Document, 'A Digital Single Market Strategy for Europe - Analysis and Evidence' SWD (2015) 100 final, 16. In that paper, the Commission had defined platforms as 'softwarebased facilities offering two or even multi-sided markets where providers and users of content, goods and services can meet'. This was confirmed by European Commission Vice President Ansip who informed the House of Lords that there was no single, universally accepted definition of platforms and that 'when different people are talking about platforms, they have a totally different understanding' of the term. House of Lords, 'Online Platforms' (n 17) 48.

${ }^{30}$ This is a point that was made to the House of Lords by several contributors to its investigation into online platforms. TechUK suggested that the broad definition of platform is 'not instructive in
} 


\section{B. THE UNDER-INCLUSIVENESS OF THE TERM 'POWER'}

The second problem with the notion of 'platform power' is that the power at stake is equated to the narrow concept of 'market power'. 'Market power' is a familiar concept to competition lawyers who assess its presence by reference to established price-based tests. ${ }^{31}$ A relevant market must first be defined by identifying what products and services compete for consumers before market power on that market is assessed. An undertaking (an entity engaged in an economic activity ${ }^{32}$ ) is deemed to have market power on a relevant market when it is in a position to act independently of its competitors, consumers and end-users on that market. ${ }^{33}$

As Cohen notes, this assessment of market power and market distortion dating from the industrial era - assumes that industries are well-defined, markets and choices are ascertainable and that discrete harms exist on these markets that will be amenable to targeted regulatory responses. ${ }^{34}$ These concepts have however been disrupted by the shift to an information economy. For example, pursuant to competition law, only entities that are engaged in 'economic activity' can have 'market power'. However, market power in the digital context may be a more complex, compound concept given the way new products and services are offered to individuals by building on existing offerings, and through a mixture of economic and solidarity-based initiatives. ${ }^{35}$ Moreover, as mentioned above, the primary tool for market definition is a price-based demand-side substitutability test, which gauges the reactions of consumers to small but significant price increases. If consumers would switch from product or service $\mathrm{A}$ to product or service B in the event of such a price increase, A and B compete on the same relevant market. Such a price-based test may be appropriate to measure the competitive relationship between fruit or laptops where prices are visible and understood by consumers. However, in markets where offerings are free at the point of access but subsidised through advertising or other revenue streams, traditional tools for market definition seem an odd-fit.

A further difficulty with equating power to 'market power' is that economists often fail to agree on whether market power exists. ${ }^{36}$ Market power is measured by

identifying specific problems that may occur in relation to specific platform functions and businesses' while Airbnb told the Committee that the notion of a platform does not 'necessarily illuminate any crosscutting regulatory issues that may need to be addressed'. House of Lords, Report on Online Platforms (n 17) 21.

${ }^{31}$ Commission Notice on the definition of relevant market for the purposes of Community competition law OJ [1997] C 372/5.

32 Case C-41/90 Höfner and Elser v. Macrotron GmbH (23/04/1991) ECR I-1979, [21].

${ }^{33}$ Case 27/76 United Brands v Commission [1978] ECR 207.

${ }^{34}$ Cohen, 'The Regulatory State in the Information Age' (n 11) 4-5.

${ }^{35}$ For instance, Balkin describes how the Internet facilitates 'glomming on': a strategy whereby things are appropriated from mass media and then used (for commentary, criticism, and to produce and construct things with them. Jack Balkin, 'Digital Speech and Democratic Culture: A Theory of Freedom of Expression for the Information Society' (2004) 79(1) NYU Law Review 1, 10-12. Wikipedia might be one example of this process in action.

${ }^{36}$ In a recent judgment involving an alleged abuse of dominance by Google Inc, Roth J noted of the economic experts before the Court that 'both have undoubted expertise in this field, but I found that 
looking at an array of factors, including the market share of companies operating on the relevant market and the structure and dynamics of that market. Even in the presence of high market shares, it is often argued that companies are unable to exert market power due to the constant threat of competition from emerging and new entrants as a result of low barriers to entry. For instance, whether assets such as computing resources and large datasets can constitute barriers to entry is highly contested. Tucker and Wellford argue that significant datasets have become so inexpensive as to be an option even for the prototypical garage-based start-up company' as 'relevant data are widely available and often free'. ${ }^{37}$ From this perspective, competition is just a click away. ${ }^{38}$ Others, such as Pasquale, argue that hopes of such a wave of creative destruction are naïve in view of the economies of scale and network effects evident in some digital markets. He suggests that 'even with millions in venture capital funding, even with computing space leased from Amazon, a start-up with valuable new search technology is far, far more likely to be bought up by Google than to displace it'. ${ }^{39}$ Arguments over whether market power exists therefore appear intractable. In keeping with the teachings of the Chicago School, competition authorities and regulators are encouraged to adopt a cautious, non-interventionist approach lest intervention given rise to detrimental 'false positives', and departure from this orthodoxy to investigate abuses of market power in digital markets is often met with allegations of economic protectionism on the part of relevant regulators. 40

The most compelling argument against equating the 'power' in 'platform power' to market power is therefore that the concept of market power is too narrow. Intuitively, individuals and regulators may sense that a digital company has 'power' even when market power is not present. For instance, most users would guess that the social networking site Facebook, which has 1.59 billion active users worldwide and privileged access to associated data streams, is in a position of market power. However, this position of power might not translate to a finding of 'market power' using the tests outlined above. In the past, competition authorities have not explicitly defined the user-side of the market for multi-sided services like Facebook and have instead focused on markets such as the market for online

each displayed a tendency to become an advocate for the party by which he was instructed.' Streetmap.EU Ltd v Google Inc. \& Ors [2016] EWHC 253 (Ch), at [47].

${ }^{37}$ Darren S Tucker and Hill B. Wellford, 'Big Mistakes Regarding Big Data', Antitrust Source, American Bar Association, December 2014, 1.

${ }^{38}$ To illustrate this point, reference is made to social media services such as MySpace and Bebo that once occupied visible market positions but are now virtually extinct. This example is at best inconclusive. At its peak, MySpace had 75.9 million users. Bebo has 117 million registered users (most of whom are not active). Facebook currently has 1.59 billion active users.

${ }^{39}$ Frank Pasquale, The Black Box Society - The Secret Algorithms that Control Money and Information (Harvard University Press, 2015), 82.

40 Arthur Nelson, 'Google faces antitrust action from EU competition watchdog', 15 April 2015. Available at: https://www.theguardian.com/technology/2015/apr/15/google-faces-antitrust-actionfrom-eu-competition-watchdog. 
behavioural advertising. ${ }^{41}$ In such markets, Facebook may have many competitors and a finding of market power is not evident. ${ }^{42}$ The initial challenge is therefore to find a term to describe the type of power that Internet intermediaries may exert.

\section{FROM 'PLATFORM POWER' TO GATEKEEPER}

According to Mansell, specific attention is devoted to those digital platforms that operate as 'market makers - or orchestrators - in the digital ecology value chain'. ${ }^{43}$ These market makers play a 'pivotal role in the digital ecosystem' as a result of factors such as their size, business model and connection capacity. ${ }^{44}$ Platforms may be in such a pivotal position if they are vital to the functioning of other platforms: they may have assets - such as an operating system or user-base - that are required by other entities to compete. ${ }^{45}$ Such control over access to software or to end-users may place some platforms in a position of market power ${ }^{46}$ and, if so, the actions of the platform vis-à-vis other businesses might cause harm to competition. For instance, a pivotal platform could manipulate the processing and presentation of information to its own commercial advantage ${ }^{47}$, or exercise its discretion to withdraw access to its infrastructure or users without warning. ${ }^{48}$ Competition law would intervene to end these practices if, overall, they had a net negative impact on 'consumer welfare' and led to, for instance, increased price or lower quality products. ${ }^{49}$ However, it is suggested that platforms that control access to infrastructure and users, and are therefore in a 'pivotal position', may also have implications for individuals that are not captured by economic and

\footnotetext{
${ }^{41}$ See, for instance, the Commission's market definition in the Microsoft/Yahoo! Search Business merger (COMP/M.5727 Microsoft/Yahoo! Search Business) paras 85-87.

42 Pasquale accuses some scholarship of promoting the 'structural production of ignorance', by "characterising scenarios as "consent" and "competition" when they are experienced by consumers and users as coercive and manipulative'. Frank Pasquale, 'Privacy, Antitrust and Power' (2013) George Mason Law Review 1009, 1011.

${ }^{43}$ Mansell, 'Platforms of Power' (n 22) 25.

${ }^{44}$ This is noted in a document prepared by EU digital commissioner Günther Oettinger's office that was leaked to the press (see further, Quartz, 'These documents reveal the EU's thoughts on regulating Google, Facebook, and other platforms', 23 April 2015, http://qz.com/389905/these-documents-revealthe-eus-thoughts-on-regulating-google-facebook-and-other-platforms/). This internal document (available here: http://oehv.at/OEHV/files/92/92af2b4c-b0b0-4e33-97ee-30cc7d9fad8c.pdf) notes that in the near future 'only a very limited part of the economy will not depend on them in the near future' and therefore queries whether they might be labelled 'systemic actors'.

45 TNO report, 'Digital Platforms' (n 21) 14.

46 Ibid. The French CNNum has observed that 'certain platforms have managed to stand out from competitors by ... maintaining control over each point in their user access channels, ie. Internet browsers, logistics, operating systems, terminals and other connected devices, etc.' CNNum, 'Platform Neutrality' (n 12) 5.

${ }^{47}$ European Commission, DSM - leaked document (n 44) 2.

48 Ibid.

49 According to the European Commission in its Guidance on Article 102 TFEU consumer welfare means that consumers 'benefit from competition through lower prices, better quality and a wider choice of new or improved goods and services' (European Commission, Guidance on the Commission's enforcement priorities in applying Article 82 of the EC Treaty to abusive exclusionary conduct by dominant undertakings OJ [2009] C 45/7, [5]).
} 
competition law analysis. These implications are better reflected by the 'gatekeeper' notion than by the concept of 'platform power'.

The concept of a network 'gatekeeper', credited to Barzilai-Nahon, is not exclusive to the digital environment. ${ }^{50}$ At its most simple, a 'gatekeeper' determines what can, and cannot, pass through a gate. Laidlaw further specifies that gatekeepers are non-state actors that have the capacity to alter the behaviour of others in circumstances where the state has limited capacity to do the same. ${ }^{51}$ This movement away from state actors towards the exercise of quasi-regulatory powers by private actors leaves a potential gap that regulatory initiatives in the field are grappling to define and to fill. Laidlaw argues that traditional gatekeeper theory sees the gatekeeper as 'somehow uninvolved, or the gated as being unaffected, at least in the sense that the focus is purely on gated misconduct rather than gated rights as well'.52 She therefore proposes a more dynamic assessment of internet gatekeepers, differentiating between two types: 'Internet gatekeepers' who control information flows and 'Internet information gatekeepers' which as a result of this function of controlling information flows can have an impact on 'participation and deliberation in democratic culture'. While we might impose liability on Internet gatekeepers for their failure to take a particular action (for instance, acting expeditiously to take down defamatory content from their platform), she argues that additional responsibilities can be imposed on 'Internet information gatekeepers' given their 'power and control over the flow, content and accessibility of information'. ${ }^{53}$ It is this latter concept that is of relevance in this context. Although an Internet information gatekeeper (hereafter gatekeeper) may have 'market power' in the sense outlined above, such power is not indispensable: 'gatekeeper' theory is concerned with power over information flows. Gatekeeper power is therefore distinct from market power in terms of how it is measured, and in terms of its potential impact on the rights and interests of individuals.

The notion of a gatekeeper, as expanded upon by Laidlaw, therefore offers a more accurate account of online power than the concept of 'platform power'. However, two alterations to Laidlaw's theory are suggested here. First, the paradigm of 'influence on democratic culture' Laidlaw uses to justify the imposition of more robust responsibilities on Internet information gatekeepers may not perfectly reflect the concerns gatekeepers entail. It could, for instance, be considered that any action of a gatekeeper that hinders individual autonomy or dignity might merit regulatory attention even in the absence of an influence on

50 Karine Barzilai-Nahon, 'Toward a theory of network gatekeepeing: A framework for exploring information control' (2008) 59(9) Journal of the American Society for Information Science and Technology 1493.

51 Emily Laidlaw, 'A framework for identifying Internet information gatekeepers' (2010) 24(3)

International Review of Law, Computers \& Technology 263, 265.

52 Laidlaw, 'Internet information gatekeepers' (n 51) 267.

53 Ibid. 266. 
democratic culture. Secondly, gatekeeping in the digital context implies more than merely control over information flows. As Helberger et al argue, much of the concern regarding the influence of gatekeepers lies in their control over access to individuals and the way in which the relationship between gatekeepers and users is shaped, rather than their control over access to information. ${ }^{54}$ This echoes Zuboff's claim that if 'power was once identified with the ownership of the means of production, it is now identified with the ownership of the means of behavioural modification'. ${ }^{5}$ It is this broader notion of gatekeeper, encompassing these two alterations, that is preferred in this paper.

The shift in focus from 'platform power' to the consequences of the actions of 'gatekeepers' is not purely cosmetic. It entails a shift from an entirely structural approach (focusing on platforms because they are multi-sided or digital, for instance) to an approach that also encompasses functional aspects (focusing on gatekeepers because of their role in controlling the flow and accessibility of information and structuring the digital environment). Thus, this approach has the benefit of displacing a specific technology - namely, platforms - as a regulatory target and instead focusing on potentially problematic functions. As BennettMoses highlights, new technologies beg the question of how they fit into 'a preexisting legal and regulatory landscape' and 'thinking of the problem in terms of "regulating technologies" seems to begin the story at the wrong time." 56 However, the very fact of being a gatekeeper is not sufficient in itself to justify regulation. This forces us to consider whether gatekeepers raise distinct regulatory concerns that may justify alterations to the regulatory regime that currently sustains gatekeepers.

In the next section, two sets of concerns regarding digital gatekeepers will be identified and examined: first, concerns regarding access to and presentation of content and services and, second, concerns regarding data processing and profiling. These concerns are not exhaustive. Rather, these examples serve merely to illustrate that not all harms to individuals are captured by the ex post application of competition rules, or visible from a purely economic perspective. In particular, rights such as freedom of expression, data protection, privacy and autonomy are not given any additional weight in economic analysis despite their normative importance. This is an important point as opponents to regulation argue that it is unnecessary given the potential for ex post competition law intervention. If competition law cannot capture these concerns, then it cannot act as a viable alternative to regulation.

\footnotetext{
${ }^{54}$ Natali Helberger, Katharina Kleinen-von Königslöw and Rob van der Noll, 'Regulating the new information intermediaries as gatekeepers of information diversity' 2015 (17)(6) Info 50, 51.

55 Shoshana Zuboff, 'Big other: surveillance capitalism and the prospects of an information civilization' (2015) 30 Journal of Information Technology 75, 82.

56 Lyria Bennett-Moses, 'How to Think about Law, Regulation and Technology: Problems with “Technology” as a Regulatory Target' (2013) 5(1) Law, Innovation and Technology 1, 17.
} 


\section{A THEORY OF 'GATEKEEPER' HARM?}

The concerns motivating calls for the regulation of platform power differ dramatically, ranging from commercial concerns (that a platform will quash competition, for instance) to social concerns (for example, that platforms are exploiting their 'suppliers' by classifying them as independent contractors rather than employees ${ }^{57}$ ). As Cohen notes, we do not yet have coherent methods to identify or describe systemic threats in the information society. ${ }^{58}$ Moreover, there are obstacles to identifying potential concerns stemming from the activities of gatekeepers: most evidently, the opacity surrounding the actions and offerings of gatekeepers makes it difficult to identify potentially harmful conduct, or to assess its scale. For instance, it is difficult for users of search engine services to evaluate the quality of the search results they obtain, or to know whether these results are 'neutral' or are designed to engender a particular reaction. ${ }^{59}$ This is coupled with the problem that the concerns identified are diffuse and lack a common thread or unifying theme. Their articulation is consequently more complicated and potentially less compelling, particularly when compared to the tangible benefits society derives from platforms ${ }^{60}$ and the quantifiable costs of regulating. Bearing these challenges in mind, this section examines two examples in order to highlight that gatekeepers can have an influence on human rights and freedoms, such as freedom of expression, privacy, data protection and freedom of association, and that this influence falls into a blind spot when the activities of gatekeepers are viewed solely through the lens of neoclassical economic theory.

\section{A. GATEKEEPER CONTROL OVER ACCESS TO INFORMATION}

Gatekeepers control information flows and access to individuals and shape the relationship between users and platforms. There are some limited exceptions to this monopoly, for instance States may prohibit access to or possession of certain content such as child abuse images ${ }^{61}$, yet even in these circumstances the State often enlists the help of a gatekeeper in order to police and enforce these laws, for example in the Internet Watch Foundation helps the State to combat the

\footnotetext{
${ }^{57}$ Joe Kennedy, 'Why Internet Platforms Don't Need Special Regulation', Information Technology and Innovation Foundation (ITIF) report, 8. Available at http://www2.itif.org/2015-internetplatforms.pdf? ga=1.28755130.780822210.1457138296.

${ }_{58}$ Cohen, 'The Regulatory State in the Information Age' (n 11) 5.

${ }^{59}$ See, for instance, Mark R Patterson, 'Google and Search Engine Market Power' Harvard Journal of Law \& Technology - Occasional Paper Series, July 2013 1, 11 and 25. Patterson suggests that search engine results are, in part, credence goods: it is difficult for customers to evaluate them even after they have been used.

60 Oxera, 'Benefits of online platforms' (prepared for Google) October 2015. Available at: http://www.oxera.com/getmedia/84df70f3-8fe0-4ad1-b4ba-d235ee50cb30/The-benefits-of-onlineplatforms-main-findings-(October-2015).pdf.aspx?ext=.pdf.

${ }_{61}$ See, s. 160(1) of the Criminal Justice Act 1988.
} 
dissemination of child abuse images. ${ }^{62}$ In a digital world, gatekeepers therefore have primary responsibility for enabling or disabling our access to and dissemination of information as well as for determining the terms on which this access and dissemination occurs. In practice therefore gatekeepers determine the extent to which individuals can enjoy the benefits of established rights and freedoms, such as the right to freedom of expression. For instance, it is widely accepted that the "power to include, exclude and rank is the power to ensure that certain public impressions become permanent, while others remain fleeting'. ${ }^{63}$ Similarly, the suggestions offered by 'autocomplete' tools by gatekeepers can influence individual perceptions. ${ }^{64}$ This potential to impact public perception has implications for fundamental rights that are not captured by a purely economicsbased approach, such as that taken by competition law. An example will illustrate this point: the exclusion of rights-enhancing applications from operating systems controlled by gatekeepers.

\section{i. Exclusion of content by gatekeepers}

Gatekeepers can allow or prevent providers of content, goods and services from accessing individuals. If a gatekeeper blocks the route between providers and individuals this action may have a negative impact on certain rights and policy interests. Most significantly, gatekeepers have a direct impact on the rights to privacy and data protection as a result of their role in setting privacy and data use conditions for all applications using their software. The UK Competition and Markets Authority (CMA) has noted that operating systems are:

responsible for the Application Programming Interfaces (APIs) which dictate how the software and hardware interact - including what information the app can access. APIs control the release of information according to the privacy controls in place at the [operating system] level. ${ }^{65}$

The operating system gatekeeper therefore determines to what extent key data protection principles are promoted. Reports suggest that gatekeepers are doing little to promote key data protection principles, such as data minimisation ${ }^{66}$,

\footnotetext{
62 For further information on the activities of the Internet Watch Foundation visit: https://www.iwf.org.uk/.

${ }_{63}$ Pasquale, The Black Box Society (n 39) 14.

${ }^{64}$ Consider the controversy in the UK when it was reported that Google search engine's failure to offer a suggested 'autocomplete' search term when individuals entered the words 'Conservatives are' in the search engine yet offered several autocomplete suggestions when terms relating to rival political parties (for instance, 'Labour are') were entered into the search engine. The New Statesman, 'Why doesn't Google autocomplete "Conservatives are..."?', 3 February 2016. Available at: http://www.newstatesman.com/politics/media/2016/02/why-doesn-t-google-autocompleteconservatives-are.

${ }^{65}$ CMA, 'The commercial use of consumer data: Report on the CMA's call for information', CMA38, June $2015,42$.

66 Article 6(1)(c) of the Data Protection Directive (European Parliament and Council Directive 46/EC of 24 October 1995 on the protection of individuals with regard to the processing of personal data and on
} 
amongst application providers. For example, a 2014 survey conducted by the Global Privacy Enforcement Network (GPEN) discovered that one third of all applications requested an excessive number of permissions to access additional personal information. ${ }^{67}$ Moreover, the FTC has also taken actions against applications such as Brightest Flashlight and Snapchat in recent years for misrepresenting how the personal data they gather is used.68 In addition to determining the terms on which applications can operate (and process data), gatekeepers can also demand that applications provide them with access to customer data. For instance, it is well documented that the Financial Times withdrew its application from the Apple App store when it was forced to provide Apple with its consumer data. The news provider went on to launch a Web-based version of its mobile app in a bid to retain reader interest. ${ }^{69}$ Smaller news outlets have chosen not to provide an app in a bid to retain custody of their user data. ${ }^{70}$

Gatekeepers can also have a significant indirect impact on the rights of individuals by blocking the route between individuals and providers. Pasquale provides the example of Apple's exclusion of the 'Drone +' application from its App Store. The Drone + application provided users with real-time alerts of drone strikes reported in the media. In this way, users of the application who wished to gain access to publicly available information about under-reported military drone strikes could obtain it in a user-friendly format. The application was rejected from the App Store twice: first on the grounds that it was 'not useful' and subsequently on the basis that it was 'objectionable and crude'. ${ }^{71}$ The exclusion of the application illustrates that the actions of gatekeepers can have an impact on opinion formation and the autonomy of Internet users ${ }^{72}$ and that gatekeeper transparency is this critical.73 It might be argued that other sources of this information remained available, and that all editorial decision-making necessarily implies the exclusion of some information. What is different in this context is the

the free movement of such data [1995] OJ L281/23) states that personal data must be "not excessive in relation to the purposes for which they are collected and/or further processed'.

${ }^{67} \mathrm{CMA}$, 'The commercial use of consumer data' (n 65) 123.

${ }^{68}$ Ibid. 123-124.

69 Reuters, 'Financial Times pulls its apps from Apple Store', 31 August 2011 (http://www.reuters.com/article/us-apple-ft-idUSTRE77U1O020110831).

${ }^{70}$ Helberger et al, 'Regulating the new information intermediaries' (n 54) 56.

${ }^{71}$ Pasquale, The Black Box Society (n 39) 62.

72 Competition lawyers reject the suggestion made by some authors that Google could be likened to public utilities (such as rail or electricity providers) or essential facilities. See, for instance, Marina Lao, 'Search, Essential Facilities and the Antitrust Duty to Deal' (2013) Northwestern Journal of Technology and Intellectual Property 275.

73 The recent controversy following the 'revelation' that Facebook uses human curators in order to shape the 'Facebook trends' feature also illustrates the opacity of the operations of gatekeepers and the consequent lack of understanding of these operations. See, Sam Thielman, 'Facebook news selection is in hands of editors not algorithms, documents show', The Guardian, 12 May 2016 (https://www.theguardian.com/technology/2016/mav/12/facebook-trending-news-leaked-documentseditor-guidelines) or Deepa Seetharaman, 'Facebook's Curators Shape “Trending” News Feature' Wall Street Journal, 12 May 2016 (http://www.wsi.com/articles/facebooks-curators-shape-trending-newsfeature-1463095472). 
role of Apple's architecture (or code) in the decision-making context. Apple devices are automatically, and necessarily, routed through the Apple App Store 'walled garden'. ${ }^{74}$ Apple's choices are therefore the choices of the user, and the user should be aware of the factors informing Apple's decisions to include and exclude from its App Store. As Mansell suggests, 'citizens cannot choose to view what they are not aware of or to protest about the absence of content which they cannot discover'. ${ }^{75}$

A complaint filed with the European Commission by the provider of a privacy enhancing technology (PET) provides a further illustration of how gatekeepers can influence the extent to which individuals can exercise their rights. Disconnect complained to the Commission that Google had excluded one its applications from Android's Google Play application store thereby abusing its position of market power on the market for mobile handset operating systems. ${ }^{76} \mathrm{It}$ argued that this exclusion from the Google Play store unfairly discriminated against its application and gave Google's own rival software a competitive advantage. The Disconnect application in question prevents third parties from tracking Android users when they browse the web or use applications on their devices. This tracking is used to gather data to improve the targeting of advertising but can also facilitate the installation of malware on devices. Google responded informally by highlighting that it applies its policies consistently to all applications and that it has 'long prohibited apps that interfere with other apps - such as altering their functionality, or removing their way of making money'. ${ }^{77}$ It also emphasised that there are over 200 privacy applications available in Google Play that comply with its policies. This example again illustrates the indirect impact that gatekeepers can have on the exercise of rights: by blocking a PET - a technology designed to enhance privacy - a gatekeeper can make it more cumbersome for an individual to exercise privacy and data protection rights. While again the impact on rights might be minimal given the availability of competing PETs, again it highlights that in the absence of an objective and transparently applied policy for the inclusion of applications on a (gatekeeper) software platform, the gatekeeper can have an impact on the rights of individuals.

\footnotetext{
74 A 'walled garden' is a closed environment (for instance, an operating system) where the operator controls access to the applications, content and services that can be accessed. By only allowing approved apps into the Apple App Store, Apple seeks to ensure better interoperability, synching and security however this closed system may also limit user autonomy. Brian Meyer, 'Why is iOS a Walled Garden?', Apple Gazette, 13 November 2013 (http://www.applegazette.com/opinion/why-does-apple-hide-ios-ina-walled-garden/).

${ }_{75}$ Mansell, 'Platforms of power' (n 22) 8.

76 Alistair Barr, 'App Maker Files EU Complaint Against Google, Alleging Abuse of Android Dominance', 1 June 2015. Available at: http://www.wsj.com/articles/app-maker-files-eu-complaintagainst-google-alleging-abuse-of-android-dominance-1433204706\#:mdP9UIcFB3W9ZA.

${ }_{77}$ Foo Yun Chee, 'Privacy app maker files EU antitrust complaint against Google', 2 June 2015. Available at: http://www.reuters.com/article/us-eu-google-antitrust-idUSKBN0OI1Z220150602.
} 


\section{ii. The limits of a purely economic approach}

It is clear from the Drone + and Disconnect examples above that the actions of the gatekeeper have the potential to enhance the effectiveness of fundamental rights, or at the other end of the spectrum, lead to their breach. Competition law is not designed to capture these fundamental rights implications. For example, for Disconnect's complaint to clear the first hurdle, a competition authority would need to establish that Google's Android operating system has market power. Despite its high market shares, it has been argued that Android's market power is 'weaker than supposed' because it competes directly with other operating systems 'every time a consumer buys a new phone' on the basis of the 'number and quality of the apps available'. ${ }^{78}$ Thus, an operating system would become less attractive to users if it excluded (arbitrarily or otherwise) applications from its operating system. ${ }^{79}$ This logic assumes that individuals make their decision to buy a particular handset based on the applications offered. However, in reality a multitude of factors are at play, with the choice of applications playing a minor role when compared to considerations such as price and handset quality. More importantly, such an argument ignores the reality of information asymmetries (how many users know that the Drone+ application has been excluded from the Apple app store?) and consumer lock-in (consumers may only have the opportunity to change providers infrequently due to contractual and other practical constraints, such as network coverage). Given these variables, even establishing a position of market power may be impossible for competition authorities.

However, even if a competition authority could establish that a gatekeeper had market power, competition analysis would not capture intangible harms, such as harms to fundamental rights. Rather, competition law seeks to protect specified parameters of competition - namely price, quality, choice and innovation - that enhance 'consumer welfare'. An example will illustrate this point. In its Facebook/Whatsapp merger decision, the European Commission concluded that Facebook's acquisition of instant messaging service Whatsapp would not impede effective competition between the two companies. ${ }^{80}$ It was able to reach this conclusion as it held that Facebook and Whatsapp were not close competitors (and competition could not be impeded when it does not exist). However, an argument could be made that the consolidation of data sets facilitated by this merger impedes effective individual control over personal data as individuals would not have anticipated such consolidation and may lack the power (and information) to contest this acquisition or mitigate its effects. For those who objected to the acquisition on fundamental rights grounds, the only option was to withdraw from Facebook and Whatsapp services. In short, the result was

${ }^{78}$ ITIF, 'Why Internet Platforms Don't Need Special Regulation' (n 57) 10.

79 Ibid.

80 COMP/M.7217 Facebook/WhatsApp, [191]. 
impoverished choice for individuals regarding the terms of their data use yet this result was unproblematic from a competition law perspective. ${ }^{81}$

Competition scholars will rightly argue that it is not the role of competition law to tackle such fundamental rights concerns. This being so, competition law should not be offered as a solution to all problems caused by gatekeeper practices. These examples also caution against a purely economic approach to the question of gatekeeper regulation, as encouraged by some stakeholders. ${ }^{82}$ Such an approach may lead to blind spots as the 'rights-enhancing' role of the applications is not given any additional normative weight: for instance, a PET would be treated in the same way as an application that provides transport information or a digital abacus. Indeed, a PET may even be viewed as inefficient as it blocks flows of information that are assumed by many regulators to promote efficiencies. For instance, the CMA suggests that efficient markets may involve data sharing to 'minimise the costs in multiple firms collecting, storing and processing the same data multiple times' and failing to share, sell or license personal data may 'be a further source of inefficiency in data markets, leading to increased costs for consumers and firms' ${ }^{83}$ This presumption that increasing flows of information and data sharing is efficient may, of course, be contested. For example, data sharing can also increase costs when data need to be corrected or updated in order to render them accurate. Yet, even if this PET is economically inefficient, it renders data protection rights more effective by allowing individuals to easily express their data processing preferences and have the application assess whether these preferences are respected by other applications and services the individual wishes to use. PETs thus give individuals more control over their personal data.

More fundamentally, the Disconnect example highlights that when there is a conflict between gatekeeper and societal interests, gatekeeper interests will prevail. As Mansell notes a 'platform owner's interest is in aggregating content and shaping traffic flows ultimately to achieve profits and to command high visibility in the media marketplace ecology'. ${ }^{84}$ In other words, it is the duty of gatekeepers to advance the interests of their shareholders. While it is recognised that these interests may be multi-faceted given the numerous, diverse shareholders in the context of complex corporate structures, it remains that these private interests may not align with public policy objectives and where they do not the former will prevail. 85 Therefore, when there is a tension between the monetary and the

\footnotetext{
${ }^{81}$ Pasquale has critiqued this emphasis in the context of other transactions, arguing that by 'focusing myopically on efficiency gains that can be temporary or exaggerated, [competition authorities] gloss over the long-term pathologies of corporate concentration.' Pasquale, 'Privacy, Antitrust and Power' (n 42) 1010.

82 For instance, Microsoft has expressed its hope that the Commission's work in this field 'produces a thorough, thoughtful, economically-grounded analysis of the complex and multi-sided platform ecosystem'. House of Lords, 'Online Platforms' (n 17) 14.

${ }^{83} \mathrm{CMA}$, 'The commercial use of consumer data' (n 65) 75.

${ }^{84}$ Mansell, 'Platforms of power' (n 22) 22.

${ }^{85}$ Indeed, Zuboff goes further and argues that surveillance capitalism (which she defines as the emergent logic of accumulation in the networked sphere) thrives on the public's ignorance. Zuboff, 'Surveillance capitalism' (n 55) 83.
} 
dignitary value of personal data, the rational gatekeeper can be expected to further its own interests. ${ }^{86}$ One of the over-arching problems here is that we have limited knowledge of when such conflicts occur, and how they are handled.87 This is something that Pasquale highlights in relation to Apple's exclusion of the Drone+ app: 'although the "objectionable content" guidelines at Apple are well publicized, the way they are applied is not' leaving decisions on what applications to exclude from the App Store to arbitrary discretion.

Thus it can be seen that gatekeepers control what content we access and the terms on which this content can be accessed. The terms on which this control is exercised are under-publicised and individuals therefore lack the knowledge and power to have a disciplining influence on gatekeepers. This control can have ramifications for fundamental rights that are not captured by competition law analysis due to their nature (intangible implications) and scale (while they may have significant consequences for some individuals, they may be deemed minimal in overall terms).

\section{B. GATEKEEPER CONTROL OVER PERSONAL DATA PROCESSING}

By definition, gatekeepers control - amongst other things - information flows, including flows of personal data. Flows of personal data are, to a large extent, regulated by data protection legislation. ${ }^{88}$ This legislation applies when 'personal data' are 'processed'. ${ }^{89}$ 'Personal data' and 'processing' are broadly defined and, as a result, many of the potential harms of data processing by gatekeepers may be captured by data protection legislation. For instance, the concentration of data in the hands of a gatekeeper, like other organisations, may entail a heightened risk of data security breach. ${ }^{90}$ Provisions in data protection legislation (theoretically) mitigate such a risk by placing an obligation on data controllers to respect the principle of data minimisation and to ensure that data processing systems are structurally robust. ${ }^{91}$ This is just one of multiple examples that illustrates how the

\footnotetext{
86 'As middlemen, they specialize in shifting alliances, sometimes advancing the interests of customers, sometimes suppliers: all to orchestrate an online world that maximizes their own profits'. Pasquale, The Black Box Society (n 39) 5.

87 Ibid. 61.

${ }^{88}$ In particular, the Data Protection Directive (n 66).

89 Personal data is defined in Article 2(a) of the Directive as 'any information relating to an identified or identifiable natural person' while 'processing of personal data' is defined in Article 2(b) as 'any operation or set of operations which is performed upon personal data'.

90 CtrlShift, 'The data driven economy: Toward sustainable growth', 16. Available at: http://thedatadriveneconomy.com/. Daniel Solove, 'Identity Theft, Privacy and the Architecture of Vulnerability' (2003) 54 Hastings Law Journal 1, 28.

91 For instance, under EU data protection legislation 'appropriate technical and organisational measures' must be adopted to protect against 'accidental or unlawful destruction, accidental loss or alteration of data'. The Court of Justice has held that such principles of data protection and data security constitute the essence of the EU Charter right to data protection. Joined Cases C-293/12 and C-594/12 Digital Rights Ireland Ltd v Minister for Communications, Marine and Natural Resources and Others and Kärntner Landesregierung and Others [2014] ECR I-238, [39].
} 
activities of gatekeepers are regulated by data protection law. However, the strategic role of gatekeepers in the personal data processing ecosystem can have detrimental effects on individuals that are not captured by data protection law, as shall be outlined below.

\section{i. Gatekeeper power and profiling practices}

By collecting and sorting data, gatekeepers can profile users of their platforms, and in this way individuals become visible or legible to gatekeepers. ${ }^{92}$ The techniques used to profile or categorise individuals have been clearly outlined by the CMA in its report on uses of consumer data, and by the FTC in its report on data brokers. ${ }^{93}$ The broader implications of this profiling have also been widely discussed. ${ }^{94}$ However, there are several implications that may be particularly acute in the context of gatekeeper data processing that merit further consideration.

One of the primary concerns regarding gatekeepers is their potentially superior ability to profile individuals based on what Pasquale labels a 'selfreinforcing data advantage'. ${ }^{55}$ This profiling facilitates personalisation which in turn leads to a risk of 'filter bubble" 96 : that individuals will be offered content and services that appeal to their current interests, thereby consolidating and reinforcing existing prejudices and preferences.

In addition to this risk, profiling can enable gatekeepers to differentiate and discriminate between individuals as well as to manipulate them. An important source of personal data to profile individuals is data gathered online, via tools such as first and third party cookies, about browsing and purchasing patterns of individuals. These profiles are used to categorise individuals according to their perceived interests, personal characteristics and socio-economic status amongst others. Tailored goods and services are then offered to individuals on the basis of this categorisation. This categorisation may escape the application of data protection legislation if, on the basis of the profile, the individual is no longer identifiable. ${ }^{97}$ As proponents of behavioural advertising regularly assert, an

\footnotetext{
${ }^{92}$ Linnet Taylor, 'Data subjects or data citizens? Addressing the global regulatory challenge of big data' in Freedom and Property of Information: The Philosophy of Law Meets the Philosophy of Technology (Mireille Hildebrandt and Bibi van den Berg, eds, forthcoming 2016).

${ }^{93}$ FTC, 'Data Brokers: A Call for Transparency and Accountability', May 2014; and, CMA, CMA, 'The commercial use of consumer data' (n 65).

94 See, for instance, Frederik Borgesius, 'Improving Privacy Protection in the Area of Behavioural Targeting' (Kluwer, 2015); Solon Barocas and Andrew Selbst, 'Big Data's Disparate Impact' (2016) 104 California Law Review 671.

95 Pasquale, 'Privacy, Antitrust and Power' (n 42) 1015.

${ }^{96}$ Eli Pariser, The Filter Bubble: What the Internet is Hiding From You, (Viking, London, 2011).

${ }^{97}$ For instance, if a third-party cookie tracks an individual across a range of interconnected websites collecting consumer data as the individual browses, it may not necessarily be possible to link this data back to an identifiable individual. In this instance, data protection legislation would not apply to the resultant profile as it is not 'personal data'. See, Solon Barocas and Helen Nissenbaum, 'Big Data's End Run Around Procedural Privacy Protections' Communications of the ACM, Vol. 57 No. 11: November 2014, and Frederik Zuiderveen Borgesius, 'Singling Out People Without Knowing Their Names Behavioural Targeting, Pseudonymous Data, and the New Data Protection Regulation' (February 16, 2016) (Available at SSRN: http://ssrn.com/abstract=2733115).
} 
advertiser has no interest in the actual identity of an individual. ${ }^{98}$ Rather, an advertiser is simply concerned with being able to determine whether an individual is more likely than others to be interested in, or to pay more for, a particular type of good or service. It is the ability to differentiate between 'individually' aggregated patterns of purchase and search rather than to identify individuals that is important. Therefore, if an individual attends marriage counselling and is profiled on this basis, a credit card company does not need to know his name, or the name of his partner, in order to offer him higher priced insurance products. The mere fact of falling within a 'attends marriage counselling' category may be sufficient to classify an individual as more likely to default when offering insurance products. ${ }^{99}$ As mentioned above, such anonymous profiling will fall outside the scope of data protection regulation. Moreover, tailoring the goods and services offered to individuals in this manner may not amount to discrimination: this is because it does not differentiate between individuals on the basis of protected characteristics such as race, gender, religion and age.

This differentiation may be problematic for different reasons. Profiling can be used to differentiate between consumers based on the quality or the price of goods and services offered to them. As the CMA notes, the 'collection of consumer data may enable firms to make judgments about the lowest level of quality needed by consumers/groups of similar consumers. This may enable a firm to engage in quality discrimination where quality differences are not reflected in the price of goods or services.' 100 In practice, a gatekeeper could facilitate such a practice by restricting the products that are displayed to consumers or changing the order in which they are listed to display poorer quality products first in some circumstances. ${ }^{101}$ Amazon's infamous 'dynamic pricing' experiment provides an illustration of how profiling might be used to offer products to individuals at differentiated prices based on their assumed reserve price.102 While this differentiation falls short of discrimination, it takes advantage of the information asymmetry between the individual and the profiler, to the disadvantage of the individual. The profiler will attempt to gauge the reserve price of the individual the maximum cost he or she is willing to pay, or the lowest quality he or she is willing to accept - and make an offer on this basis. An individual may therefore pay more than he or she needed for goods or services, allowing the company to extract more profit from their offerings and thus entailing a 'transfer of wealth from the pockets of consumers to the pockets of operators'. ${ }^{103}$

98 Thomas M. Lenard and Paul H. Rubin, 'In Defense of Data: Information and the Costs of Privacy' (2010) Policy \& Internet 150, 165.

${ }_{99}$ Pasquale, The Black Box Society (n 39) 31.

${ }_{100}$ CMA, 'The commercial use of consumer data' (n 65) 93.

101 Ibid. 93

102 Alessandro Acquisti, 'The Economics of Personal Data and the Economics of Privacy' Joint WPISPWPIE Roundtable OECD, 1 December 2010, 19: http://www.oecd.org/sti/ieconomy/46968784.pdf. ${ }^{103}$ House of Lords, 'Online Platforms' (n 17) 75. 
In addition, studies conducted by the UK Office of Fair Trading (OFT) on online targeted advertising and pricing, indicate that certain misleading pricing techniques could 'result in consumers making purchasing decisions they would not have made were prices more clearly advertised, or spending more than they needed to'. ${ }^{104}$ Such profiling can therefore prey on user vulnerability. This may be even more evident in the case of those classified as 'financially challenged' 105 who may be targeted with payday loans, or those classified as 'risk takers' who might be offered gambling opportunities etc. 106

An overarching concern is the opacity of these personalisation practices. Writing in the media plurality context, Hellberger et al conclude that while gatekeepers do not necessarily have a negative impact on media plurality given the ranger of news outlets available online, it should

be considered problematic that users have no knowledge of the selection criteria on which the processes of implicit personalisation are based and that they are not provided with any tools to change them or "turn them off". Thus, they are unable to assess how limited their news selection is. ${ }^{107}$

Pasquale also highlights this opacity stating that there may be 'scarlet letters emblazoned on our digital dossiers' that we may not even know about. ${ }^{108}$ These problems may be exacerbated when the profile is incorrect, and does not reflect the individual's actual spending power, personal interests or characteristics. ${ }^{109}$ However, this lack of knowledge is not the sole problem. Indeed, some gatekeepers give individuals the option to view and to amend the parameters that are used to generate their profiles, thereby co-opting the individual into the process. ${ }^{110}$ Yet, even if an individual can view and amend the factors influencing a particular profile, he or she might not be able to challenge the inferences drawn from the profile, including the inference of disinclination or imperviousness to change. If an individual is categorised in a manner that he or she disagrees with, for instance, 'diabetic lifestyle' or 'leans left'111, a profiler may be able to argue that

\footnotetext{
104 CMA, 'The commercial use of consumer data' (n 65) 16.

105 FTC, 'Data Brokers' (n 93) 21.

106 According to the CMA, the small minority of app games players who make in-app purchases (labelled 'whales' by the industry) and who subsidise the 'freemium' model for apps, could be directed towards applications based on this model rather than other games apps using other revenue streams. CMA, 'The commercial use of consumer data' (n 65) 58.

${ }^{107}$ Hellberger et al, 'Regulating the new information intermediaries' (n 54) 56.

108 Pasquale, The Black Box Society (n 39) 34.

109 Christian Sandvig argues that one of the main dangers of algorithms is 'corrupt personalization': the use of personalization services to serve commercial interests that are at odds with our own, authentic interests (for example, when an endorsement or 'like' of particular content is applied to other content that the individual did not endorse). Christian Sandvig, 'Corrupt Personalization', 26 June 2014 (https://socialmediacollective.org/2014/06/26/corrupt-personalization/).

${ }^{110}$ For instance, Google's 'Ad Preferences' states that: 'You can control the ads that are delivered to you based on your Google Account, across devices, by editing these settings. These ads are more likely to be useful and relevant to you.'

111 FTC, 'Data Brokers' (n 93) 21.
} 
the inference is simply a matter of opinion rather than fact. ${ }^{112}$ Moreover, even if an individual knows that certain characteristics are valued, or punished, more than others when determining the terms and conditions on which goods and services are offered, this may not help them decipher how to act. A trivial example illustrates this point. Some grocery retailers that offer motor insurance use purchasing data from loyalty schemes to 'draw inferences about household characteristics - for instance, to offer discounts to households that appeared from their shopping habits to be relatively low risk'. ${ }^{113}$ However, in the endless debates over whether an occasional glass of red wine is good for you, or whether butter is better than margarine, even if an individual were to try conform to a profiler 'ideal' this may not be possible.

The risk of discrimination is an additional concern. Most evidently, as FTC Commissioner Edith Ramirez highlights, algorithmic data profiling can 'accidentally classify people based on categories that society has decided - by law or ethics - not to use, such as race, ethnic background, gender or sexual orientation.' 114 In its report on data brokers, the FTC notes that individuals are divided into segments such as 'Urban Scramble' and 'Mobile Mixers', which ostensibly focus on minority communities with lower incomes but which incorporate a high concentration of Latino and African-American consumers. ${ }^{115} \mathrm{It}$ notes that these segments may be more sensitive as a result of their reliance on characteristics, such as ethnicity, income level and education. ${ }^{116}$ While not all profiling based on protected characteristics is illegitimate (for instance, some profiling may facilitate affirmative action policies), such discriminatory profiling may serve to perpetuate existing inequalities. For example, certain groups, which have been judged un-creditworthy in the past, and therefore offered disadvantageous terms of credit that they have struggled to meet, will have their difficulties charted and held against them in data-driven lending cycles. As Pasquale notes, 'late payments will be more likely, and then will be fed into present credit scoring models as neutral, objective, non-racial indicia of reliability and creditworthiness'. ${ }^{117}$ In this way, the profiling actually increases the likelihood of a consumer defaulting. ${ }^{118}$ Perhaps of most concern is the potential for gatekeepers, most notably search ranking mechanisms, to go beyond registering perceptions and to create them. Research indicates that a Google search for Caucasian names present more neutral results than for typically African-American names. Transparency is once again critical here: without access to the underlying coding and data, it is nearly impossible to adjudicate the dispute' as to whether this is

112 Pasquale, The Black Box Society (n 39) 32.

113 CMA, 'The commercial use of consumer data' (n 65) 45.

114 Pasquale, The Black Box Society (n 39) 40.

115 FTC, 'Data Brokers' (n 93) 20.

116 Ibid.

117 Pasquale, The Black Box Society (n 39) 41.

118 Ibid. 
simply a result of Google's search optimisation. ${ }^{119}$ In sum therefore, gatekeepers are in a position to use profiles to differentiate and discriminate between individuals. While such differentiation and discrimination is not the sole purview of the gatekeeper, its effects may be exacerbated in this context given the privileged structural position enjoyed by gatekeepers and the opacity of gatekeeper operations.

\section{ii. Structural impediments to individual control over personal data}

The increase in personal data processing driven by the digitisation of data has left individuals feeling a loss of control over personal data. ${ }^{120}$ Although we are currently encouraged 'to give up on privacy in terms of collection of data (...) and to focus instead on developing principles and guidelines regarding usage' ${ }^{121}$, some individuals are taking matters into their own hands by and availing themselves of technologies, such as ad-blockers, identity masking services and 'data dirtying', to prevent or disrupt data processing practices. ${ }^{122}$ Such practices may simply end in an obfuscation arms-race, in which only the most savvy individuals will stay ahead. Normatively speaking, however, some level of control over personal information is desirable so that we can challenge or prevent data processing we deem objectionable, and ascertain how and why our data are being used when we so desire. Yet, even if we were to focus solely on the use of personal data rather than its initial collection, meaningful individual control over personal data use remains beyond the grasp of most individuals. Information on why and how data are processed is tucked away in lengthy boilerplate terms and conditions and couched in vague terms. ${ }^{123}$ For instance, one online retailer states in its privacy policy that it might share customers' profiles and e-mail addresses with 'retail partners, service providers, subcontractors and manufacturers'. ${ }^{124}$ Such sweeping statements are commonplace, and even regulators have difficulty in coming to terms with these practices without committing significant resources to their investigation. ${ }^{125}$

\footnotetext{
119 Ibid. 39.

120 According to the European Commission's Eurobarometer data protection survey, only 15\% of those surveyed felt they have complete control over the information they provide online while $31 \%$ think they have no control at all. European Commission, Special Eurobarometer 431 - data protection, June 2015 (http://ec.europa.eu/public opinion/archives/ebs/ebs 431 en.pdf).

121 Craig Mundie, 'Privacy Pragmatism: Focus on Data Use, Not Data Collection' (2014) 93(2) Foreign Affairs 28.

122 CtrlShift, 'The data driven economy' (n 90) 19. 'Data dirtying' a practice where individuals intentionally provide incorrect personal details online is also now increasingly prevalent, with a recent survey indicating that $60 \%$ of consumers in the UK engage in this practice.

${ }^{123}$ Margaret Jane Radin, 'Boilerplate: The Fine Print, Vanishing Rights, and the Rule of Law' (Princeton University Press, 2014). For a critique of the failure of data privacy regimes to recognise such asymmetries see, from an EU perspective, Bert-Jaap Koops, 'The Trouble with European Data Protection Law' (2014) 4 International Data Privacy Law 250, and, from a US perspective, Robert H Sloan and Richard Warn, 'Beyond Notice and Choice: Privacy, Norms and Consent' (2014) Journal of High Technology Law 371.

${ }^{124}$ CMA, 'The commercial use of consumer data' (n 65) 41.

125 The CMA notes that as part of its high-level call for information it was 'not able to establish a detailed picture of the various arrangements between parties and the prices paid for different types of data'. Ibid. 40.
} 
Moreover, even when individuals are offered more granular 'surface' control over their personal information, this may only serve to mask how their data are processed 'behind the scenes'. ${ }^{126}$ In this context, it is therefore a perpetual challenge to obtain freely-given, specific and informed consent, as required by data protection law: the risks of data processing are unclear, individuals engage in myopic decision making (perhaps as a result) and challenges to how or why personal data are used are often not worth the candle. Moreover, attempts to do so may often further disadvantage the individual. ${ }^{127}$ As Solove suggests, in reality:

(1) people do not read privacy policies;

(2) if people read them, they do not understand them;

(3) if people read and understand them, they often lack enough background knowledge to make an informed choice; and

(4) if people read them, understand them, and can make an informed choice, their choice might be skewed by various decisionmaking difficulties. ${ }^{128}$

\section{iii. An alternative narrative}

Viewing these concerns - stemming from profiling and loss of control over personal data - through a solely economic lens offers a different perspective. While it is acknowledged that fundamental rights can have economic rationales and ramifications (the right to property being an evident example), their interpretation and application is not driven solely by an economic logic. Rightsbased and economics-based perspectives may therefore overlap yet remain distinct. ${ }^{129}$ Let us first consider the example of profiling: profiles, like knives, may be dual (or multi) use. As a result, it could be argued that it is only in the event of systematic misuse or abuse of profiles that regulation would be appropriate. Some data brokers in the US have, for instance, categorised individuals according to an 'assimilation code', which indicates a consumer's 'degree of assimilation to the English language.' ${ }^{130}$ This categorisation may have beneficial uses: it could be used to offer language-learning opportunities to those most in need, or perhaps to simplify the language used to present data use terms and conditions to these individuals. However, it could also be used to the disadvantage of individuals: governments could use it to identify 'unassimilated' immigrants, or corporate

\footnotetext{
126 Brendan Van Alsenoy et al, 'From Social Media Service to Advertising Network: A Critical Analysis of Facebook's Revised Policies and 'Terms', 23 February 2015, 10.

127 Pasquale, The Black Box Society (n 39) 24. 'In the Heisenberg-meets-Kafka world of credit scoring, merely trying to figure out possible effects on one's score can reduce it'.

128 Daniel Solove, 'Privacy Self-Management and the Consent Dilemma' (2013) 126 Harvard L. Review $1880,1888$.

129 It is also necessary to acknowledge that, like other disciplines, there are multiple different schools of thought within economics, and what is referred to as the 'economic perspective' refers to neoclassical economics.

${ }^{130}$ FTC, 'Data Brokers' (n 93) 20, fn 51.
} 
actors could use it to bamboozle those in the category with terms and conditions presented in difficult language.

Furthermore, personalisation ensures that companies reach their target audience - those who are most likely to purchase their products or avail of their services. From a business perspective, it makes sense to sell beauty products to a woman at the time of data when her profile suggests she feels less attractive ${ }^{131}$ : this may lead to a higher conversion rate from the advertisement presented to purchases. Differentiation in the form of price discrimination may also be deemed efficient: if a company can correctly ascertain an individual's reserve price, it can ensure that each customer is offered its products or services at the maximum price they can afford to pay. Individuals who can afford to pay more would therefore subsidise individuals who can afford to pay less and more individuals would gain access to the product or service overall. ${ }^{132}$

Given this dual-use potential of profiles, it has been suggested that a more targeted approach to data profiling practices is preferable: only undesirable profiling practices should be prohibited. This assumes that the fact of collecting personal data and using it to categorise individuals is not itself a problematic practice. This assumption is difficult to reconcile with the established jurisprudence of the European Court of Human Rights (ECtHR) on the right to private life. The ECtHR has held that the 'mere' fact of systematically collecting and storing the publicly available personal data of an individual can constitute an interference with the individual's right to private life. It is irrelevant whether this systematic collection and storage of data inconveniences the applicant. ${ }^{133}$ Moreover, individuals do not waive their rights by engaging in public activities that are subsequently documented. ${ }^{134}$

Such systematic collection and storage of personal data may, like the aggregation of communications traffic data, permit very 'precise conclusions to be drawn concerning the private life of individuals' 135 and, as such, it 'is likely to generate in minds of the persons concerned the feeling that their private lives are the subject of constant surveillance'. 136 The use, or misuse, of the personal data in a way that causes prejudice to the individual is therefore not a prerequisite for a finding that the systematic collection and storage of personal data interferes with the right to private life. This prima facie interference with the right to private life is not recognised when data profiling is viewed from a purely economic perspective. It is of course true that a practice that constitutes a prima facie interference with the right to private life pursuant to Article 8(1) ECHR can still be justified - and thus lawful - if the conditions set out in Article 8(2) ECHR are fulfilled. These conditions essentially permit a violation of the right to private life if this violation

\footnotetext{
131 Pasquale, The Black Box Society (n 39) 30.

132 Hal Varian, 'Price discrimination' in Schmalensee, Richard and Robert Willig (eds), Handbook of industrial organisation (Elsevier 1989), 600.

133 Amann v Switzerland (2000) 30 EHRR 843.

134 Rotaru v Romania (App No 28341/95) (unreported) 4 May 2000.

135 Digital Rights Ireland (n 91) [27].

136 Ibid. [37].
} 
is proportionate, in accordance with the law and necessary to ensure a competing public interest. ${ }^{137}$ However, in the context of gatekeepers the personalisation and differentiation that data profiling facilitates are presumed to be economically efficient and thus desirable irrespective of the impact on privacy.

Finally, as a result of the transactional approach to personal data protection taken in most jurisdictions, it is assumed that if 'consumers choose to use services from companies that offer little to no privacy protection, that reveals a preference to spend little to nothing on (or looking for) privacy.. ${ }^{138}$ For instance, Zarsky has suggested that as Facebook and Google grew under a 'lenient privacy regime', their 'emergence might indicate a shift in public preferences regarding privacy, and the market's response to such change'. ${ }^{139}$ This, of course, ignores the fact that a 'lemons equilibrium' may now prevail: the quality of the goods and services traded have been degraded as a result of information asymmetries between individuals and those who process their personal data leaving only (poor quality) 'lemons' behind. ${ }^{140}$

It is once again therefore suggested that when a purely economic approach is adopted to the profiling and data processing activities of gatekeepers, the potential harms identified above fall in the blind spots and risk being over-looked or downplayed. This is not to say that further regulation is the only necessary or desirable solution to these potential harms. Regulators must elucidate why digital gatekeepers are distinct from other sites of concentrated power. The problematic practices that profiling may facilitate, and the loss of control individuals over personal data felt (and experienced) by individuals are not exclusive to the online environment. On the contrary, current business practices indicate that the line between 'offline' and 'online' practices is difficult to draw when it comes to the creation of profiles. Practices such as 'onboarding', whereby a data broker adds offline data into a cookie to enable advertisers to use consumers' offline activities to determine what online advertisements to deliver to them, indicate that there may be little value in taking a distinct approach to the regulation of digital gatekeepers. ${ }^{141}$ Equally, regulators must consider why the use of profiles by gatekeepers is distinct. For instance, is offering an individual a beauty product at a certain time in the day based on his or her profile different to the practice of

\footnotetext{
${ }^{137}$ Article 8(2) ECHR states that: 'There shall be no interference by a public authority with the exercise of this right except such as is in accordance with the law and is necessary in a democratic society in the interests of national security, public safety or the economic well-being of the country, for the prevention of disorder or crime, for the protection of health or morals, or for the protection of the rights and freedoms of others.'

138 Pasquale, 'Privacy, Antitrust and Power' (n 42) 1009.

139 Tal Z Zarsky, 'The Privacy-Innovation Conundrum' (2015) Lewis \& Clark Law Review 119, 167.

140 George Akerlof, 'The Market for "Lemons": Quality Uncertainty and the Market Mechanism' (1970) The Quarterly Journal of Economics 488.

141 According to the CMA report, Businesses can acquire date from online or offline first parties or third parties through purchase, licensing or exchange and some evidence suggests that 'almost any dimension of data can be purchased on users'. CMA, 'The commercial use of consumer data' (n 65) 34 and 40.
} 
selling chocolate bars and snacks at supermarket checkouts? Both, it could be argued, are psychological ploys to encourage sales.

Competition experts have suggested that there is 'no need to discard the competition playbook simply because platforms in the digital economy operate 'online". ${ }^{142}$ However, it would appear that the key attribute of gatekeepers is not 'being digital'; it is their power. Nevertheless, key questions remain to be answered regarding this power: is it the nature or degree of the power that is problematic, or is the way it is related to other configurations and forms of power? Once we have a better understanding of this power of gatekeepers, we must then consider whether this increasing power ${ }^{143}$ is sufficient, in and of itself, to warrant their regulation. ${ }^{144}$ We will need to consider whether social regulation should impose a special responsibility on firms with gatekeeper power analogous to the 'special responsibility'145 imposed on firms with market power by competition law. The structuring role of gatekeepers - directing individuals towards content and services on over one trillion webpages 146 - might itself be adequate to justify this special burden.

\section{CONCLUSION}

This paper advances two claims. The first is that a shift in focus is required from the paradigm of platform power to that of a gatekeeper. This shift will help to uncover the broader human rights and public policy issues at stake in the debate. The 'platform power' terminology is both too broad (platform) and too narrow (power, understood as market power). Moreover, by focus on regulating a technology rather than a problematic conduct or processes, regulation risks tackling the wrong regulatory target and being rendered redundant by technological change. The House of Lords echoes this finding in its report, which suggests that the Commission's consultation is 'too broadly designed to address the issues raised decisively. ${ }^{1} 47$

Identifying the correct regulatory target is however a tricky task and the concerns voiced regarding the activities of digital gatekeepers are diffuse and difficult to group in a coherent, compelling narrative. As a result, mapping a regulatory response can be challenging. In tackling this challenge, it will be helpful for regulators to bear in mind the second claim set out in this paper: that by

\footnotetext{
142 Alex Chisholm, 'Platform regulation - antitrust law versus sector-specific legislation: evolving our tools and practices to meet the challenges of the digital economy', speech delivered on 27 October 2015.

143 Nearly three-quarters $(72 \%)$ of internet users have a social media profile, compared to $22 \%$ in 2007 . CMA, 'The commercial use of consumer data' (n 65) 30.

144 ITIF, 'Why Internet Platforms Don't Need Special Regulation' (n 57) 14.

145 Case 322/81, Michelin v Commission [1983] ECR 3461, [70].

146 Commission Staff Working Document, ‘A Digital Single Market Strategy for Europe’ (n 29$) 53$.

147 House of Lords, 'Online Platforms' (n 17) 108.
} 
viewing the functioning of internet gatekeepers through a purely economic lens, concerns pertaining to individual rights will be caught in the blind spot.

This second claim could have several practical ramifications. The House of Lords recommends that the European Commission should appoint a panel of independent experts to identify priority areas for action in the digital economy and to make specific recommendations. It is suggested that any such panel must include expertise from a diverse range of backgrounds, and in particular include individuals with expertise in human rights as well as economic regulation. Competition experts acknowledge that disruptive innovation in consumer markets unsettles social norms and raises questions that 'can be couched in competition terms but actually are much, much bigger.' ${ }^{148}$ We are therefore faced with the task of identifying these bigger questions, and determining whether they should be answered by ex ante regulation. In so doing, it is necessary to recognise that the analysis of political, social and cultural dimensions of gatekeepers must accompany an economic analysis of their role. ${ }^{149}$

Ultimately, the threshold for regulatory intervention will be a high one. This is for two reasons. First, the preferred framework for regulatory intervention in the EU is cost-benefit analysis (CBA). Pursuant to this framework, regulators are encouraged to ensure that ex ante regulatory tools are targeted to specific harms to avoid disproportionate effects. However, as Cohen highlights, it is difficult to model and quantify the probability of future harm: the threat of future harm involves risk and also uncertainty, and uncertainty is by definition hard to quantify. 150 Moreover, some of the potential concerns gatekeepers may entail are invisible when a purely economic perspective is adopted or, at best, hard to put in numbers when compared to the tangible benefits offered by gatekeepers. ${ }^{151}$ It is therefore necessary to acknowledge the distributional impact of this technique of regulation. Proponents of CBA deem it to be a 'neutral, rational discourse for evaluating regulatory benefits and burdens' while those who oppose CBA argue that it 'persistently undervalues threatened harms that are diffuse, cumulative and difficult to describe in monetized, present-value terms, and that it therefore predictably works to the advantage of vested economic interests'.152 The shortcomings of using CBA to assess the need for regulatory intervention in this field cannot therefore be overcome by adding non-monetary costs and benefits to the scales, alongside monetary costs and benefits as suggested by the Dutch report

\footnotetext{
148 Alex, Chisolm, 'Giants of digital: separating the signal from the noise and the sound from the fury', speech delivered on 10 December 2014.

${ }_{149}$ Mansell, 'Platforms of Power' (n 22) 21.

${ }^{150}$ Cohen, 'The Regulatory State in the Information Age' (n 11) 17.

${ }^{151}$ It has been argued that the same is true of the benefits of platforms. 'The danger is that, because these often enormous benefits are hard to quantify, policymakers will discount them and only look at the perceived market power of the platform'. ITIF, 'Why Internet Platforms Don't Need Special Regulation' (n 57) 7.

${ }^{152}$ Cohen, 'The Regulatory State in the Information Age' (n 11) 19.
} 
on platforms. ${ }^{153}$ This problem might be further aggravated by the fact that 'economists' results provide little certainty about whether policy intervention is called for in any given case, there can be a strong inclination to do nothing until the evidence of harm is incontrovertibly clear'. ${ }^{154}$ This cautious perspective will favour a deregulatory approach.

Secondly, regulators deciding to act in this field will need to tackle with the socalled Collingridge dilemma, or pacing problem. If regulators intervene at an early stage in a technology's development, regulation might be pre-emptive and would not be based on adequate information about the technology's likely impact. Regulation would therefore risk harming innovation by 'locking in existing standards' and allowing 'today's plucky innovators [to become] tomorrow's sleepy incumbents'. ${ }^{155}$ However, if regulation is delayed to a later stage of the technology's development and deployment, the technology may be too entrenched to regulate effectively. ${ }^{156}$ Coates refers to this as the 'Goldilocks' problem, adding a third hurdle based on Schumpter's 'creative destruction'157: 'even when the porridge is just right, you still should not eat the porridge because something even better than porridge will come along soon'. ${ }^{158}$ The issue of when to intervene can lead to regulatory paralysis.

Ultimately however, even in the absence of regulation, this debate will provide regulators with the opportunity to grapple with some of the bigger issues in an era of informational capitalism, and to 'rethink major assumptions about the causes and effects of power in information markets'. ${ }^{159}$ This rethinking is overdue, given the ostensible mismatch between the economic concerns tackled by antitrust law and the non-economic concerns identified in section three. The market simply may not suffice to deliver public values that regulators wish to maintain in a digital era. ${ }^{160}$ Nevertheless, it is also important to recognise that public values and market economics may be closely connected in this context. If individuals lose trust in gatekeepers, as a result of the search results or prices they are offered, this will have a negative effect on the business model of gatekeepers. For instance, increased usage of tools such as adblockers 'threaten the revenue streams that many digital content providers rely upon'. ${ }^{161}$ It is therefore little wonder that some

\footnotetext{
${ }^{153}$ For instance, the Dutch report on platforms concludes that 'ultimately, the decision to apply a specific instrument should be based on all the relevant (monetary and non-monetary) costs and benefits in what economists call a cost-benefit or regulatory impact analysis'. TNO report, 'Digital Platforms: an analytical framework' (n 21) 39.

154 Mansell, 'Platforms of Power' (n 22) 22.

155 Chisholm, 'Platform regulation - antitrust law versus sector-specific legislation' (n 142).

${ }^{156}$ Bennett-Moses, 'How to Think about Law, Regulation and Technology' (n 56 ) 7.

${ }^{157}$ Joseph A Schumpeter, Capitalism, Socialism and Democracy (New York: Harper \& Row, 1942).

158 Kevin Coates, 'An Emerging Competition Law for a New Economy? Introductory Remarks for the Chillin' Competition Panel', 21 January 2016. Available at: http:/ / www.twentyfirstcenturycompetition.com/2016/01/an-emerging-competition-law-for-a-neweconomy-introductory-remarks-for-the-chillin-competition-panel/.

${ }^{159}$ Cohen, 'The Regulatory State in the Information Age' (n 11) 11.

160 Mark MacCarthy, 'New Directions in Privacy: Disclosure, Unfairness and Externalities' (2011) I/S: J.L. \& Policy Info Society 425, 443.

${ }_{161}$ CtrlShift, 'The data driven economy' (n 90) 16.
} 
gatekeepers are now openly recognising that 'there is greater economic, social and individual benefit in restoring trust to the market, rather than responding to or exploiting its lack'.162 If gatekeepers themselves do not act to gain and maintain this trust, the case for regulation may become easier to make.

162 Ibid. 21. 